\title{
Responsabilidad por malpraxis médica: la vía extrajudicial.
}

\author{
Medical responsibility for malpraxis: the extrajudicial \\ channel.
}

IV JORNADAS ANDALUZAS SOBRE VALORACIÓN DEL DAÑO CORPORAL

Sevilla, mayo-junio 2001

J. Hernández Moreno', M.L.Hernández Gil² y A.Hernández Gil ${ }^{3}$

\section{RESUMEN}

En este trabajo se hace un estudio crítico de la respuesta a la responsabilidad por malpraxis médica por vía extrajudicial. Se consideran en principio algunos de los problemas que tiene la vía judicial ordinaria, que pueden aconsejar otros métodos, que en ningún caso la excluyen, y el estado de la cuestión en diversos países, que han sido pioneros en la implantación de estos sistemas extrajudiciales, prestando atención especial a los de la Unión Europea y Estados Unidos.

Se examinan después estos procedimientos en nuestro país, con especial atención a la mediación, conciliación y arbitraje, haciendo un estudio conceptual y valoración de las ventajas e inconvenientes de su aplicación en la práctica, y finalmente una crítica de los mismos.

Palabras clave: malpraxis, responsabilidad, extrajudicial.

\section{ABSTRACT}

In this paper we make a critical study of the extrajudicial answer to responsibility for medical malpraxis. First some of the problems of the ordinary process of law are considered; these could induce us to consider other methods, which, however, never exclude the law; we also consider the state of the question in other countries, which have been pioneers in the implantation of these extrajudicial systems, noting particularly those of the European Union and the United States.

These proceedings are then examined in our own country, paying special attention to mediation, conciliation and arbitration, making a conceptual study and an evaluation of the advantages and disadvantages of their application in practice, with a final criticism of the same.

Key words: malpraxis, responsibility, extrajudicial.

Correspondencia: J. Hernández Moreno. C/ Doce de Agosto, 18-4º 23740 Andújar (Jaén) Tfno. 953507781

1 Doctor en Medicina. Especialista en Cirugía General y en Traumatología y Cirugía Ortopédica. Médico Forense.

2 Médico Forense de Badajoz.

3 Médico Forense de Telde (Las Palmas). 
Cuando surge un problema de responsabilidad por malpraxis médica, la Administración, la Justicia y, en definitiva, la sociedad, de modo invariable demandan o exigen que trate de evitarse en el futuro $y$, por otra parte, paliar y aliviar el perjuicio ocurrido (ya que no se puede resolver), dando explicaciones y satisfacciones a los dañados, informando y explicando toda clase de circunstancias concurrentes determinantes o desencadenantes, e indemnizando económicamente el daño causado, haciéndolo con rapidez, equidad y proporcionalidad, cuantificándolo con la mayor exactitud y precisión posible.

Aparte de la posible respuesta punitiva, reprendiendo, amonestando o castigando al posible culpable, como se hace en cualquier otra actividad, cuando se actúa con falta o negligencia (aunque esto realmente es lo menos importante a nuestro entender y de algún modo no deja de ser un factor negativo del problema).

Esta reparación se puede lograr por dos caminos:

I. La vía normal (judicial), por agravio, de la cual en modo alguno puede prescindirse, ya que en todo caso marca los criterios, tendencias y pautas a seguir, $y$, por otra parte, asegura que se observen los preceptos legales, inviolables de la responsabilidad civil y penal.

2. Una vía alternativa extrajudicial, que busca fórmulas o actuaciones, que puedan ser menos traumatizantes para el médico y a ser posibles, más beneficiosas y útiles para los perjudicados, métodos más elásticos, sin la rigidez de la ley y de la norma, y que aún respetando siempre estas, estén basadas más bien en hablar, explicar, comprender, admitir, y por otra parte compensar e indemnizar, luchando contra el círculo cerrado: malpraxis o mal resultado obtenido $\rightarrow$ descrédito y posible indemnización personal $\rightarrow$ medicina defensiva (más exploraciones, más desviación de enfermos y rechazo de enfermos de riesgo, más listas de espera, más encarecimiento de la medicina, desviación de recursos necesarios para otras asistencias, etc.), lo cual se aproxima o a veces es malpraxis en sí y cierra un círculo vicioso que a toda costa se ha de romper. [I]

- Las corrientes actuales van en ese sentido, pues se tiende a criterios de responsabilidad objetiva, basada en el riesgo en vez de la clásica "por culpa", siendo cada vez más numerosos los casos indemnizables. Por otra parte, las reclamaciones a la Sanidad Pública por vía judicial tratan de desviarse a la vía Administrativa, en la que el criterio de responsabilidad objetiva es la regla. Esta vía es más compleja, difíil, lenta y encorsetada aún que las vías penal, civil o social, por cuanto implican intervención de otras instancias (Administración, Abogacía del Estado o similares en Comunidades Autónomas, etc.) y ello ha hecho hasta ahora más difícil su utilización por posibles perjudicados y en consecuencia más necesario buscar vías alternativas, más fáciles de poner en práctica. Más aún, teniendo en cuenta la posibilidad de repercusión de la Administración contra los médicos en caso de negligencia o culpa de los mismos, sin que a lo largo del procedimiento estos hayan podido defenderse, habiendo quedado desprotegidos en el proceso.

Los problemas de la vía judicial son los siguientes:

- lentitud de las actuaciones (con dificultad para la remisión de datos, que se solicitan por parte de los Organismos Sanitarios, pidiéndose y alegando lo que es necesario y lo que no lo es), y, como consecuencia de este largo y complicado proceso, ocurre 
un enconamiento progresivo de las partes y la tendencia a reforzar las posiciones de cada una de ellas.

- Frialdad y falta de discreción y reserva, o a veces la divulgación, difusión y filtraciones de lo contenido en las actuaciones, con juicios de valor e interpretaciones gratuitas de los hechos.

Falta de elasticidad por el corsé de la ley y la rigidez en la máquina de la Justicia, que es tardía, pero cuando va para delante, es imparable.

- La falta de un buen asesoramiento médico, con la gran importancia que tiene (por lo general, solo existe el informe del médico forense en los procedimientos penales). Nadie tiene que decir cosas tan importantes en estos asuntos como el médico implicado, y por lo general no dice nada. Además, la falta de explicación del médico es por sí misma en ocasiones un importante error por omisión, pues en casos de resultados desproporcionados, aunque la praxis haya sido correcta, opera la inversión de la carga de la prueba y el denunciado debe preocuparse de dejar evidente lo correcto de su actuación, y el no hacerlo puede repercutir directamente contra él.

- La desasistencia inicial del médico por los abogados de los Colegios profesionales o de las compañías aseguradoras, muchas veces hasta muy avanzado el procedimiento, motiva errores de actitudes y comportamiento, que pueden ser perjudiciales, a veces de modo definitivo para el resultado final. Muchas veces se sacrifica al médico, en espera de informes del forense o de las decisiones del Juez para poder tener una orientación previa.

- Dificultad para ejercitar otras vías (la administrativa por más complicada y la civil por ser más cara) cuando no ha prosperado la vía penal, que con gran frecuencia se utiliza como ensayo o sonda para averiguar las posibilidades existentes. Ello supone una ventaja para el médico y la Administración, y una desventaja importante y freno (o trampa) para el demandante, que en muchas ocasiones "tira la toalla". Esto por una parte evita abusos y denuncias infundadas, mas por otra deja indefensos a personas que tienen razón, y conduce a que a veces no prosperen indemnizaciones que debieran haberse conseguido.

- Finalmente, el descrédito del médico o la "pena de banquillo" son consecuencia lógica de estas deficiencias de la vía judicial que señalamos. [2] [3] [4]

Con la vía extrajudicial alternativa se pretende garantizar las indemnizaciones de modo más ágil y satisfactorio y amparar a los profesionales sanitarios:

a. Evitando el descrédito del medico y la reacción a ello (la medicina defensiva, cuyo paradigma es mandar al enfermo a otro servicio).

b. Indemnizando el mayor número de casos posible.

c. Actuando con mayor rapidez y menos burocracia.

d. Procurando discreción y secreto en las actuaciones, con lo que se trata de evitar el descrédito del médico y general de la medicina.

e. Dándose mayor facilidad y posibilidad de adoptar nuevas posiciones o aptitudes en un momento determinado.

f. Lográndose mayor comprensión para los perjudicados o imputados, con más explicaciones e información sobre los derechos de una y otra parte, con lo que se logra más satisfacción y de algún modo "honrar a la víctima". 
g. Posibilitando mayor agilidad y elasticidad para la evaluación de las indemnizaciones.

h. Abaratando los costes y ajustándolos al incremento del $n^{\circ}$ de casos indemnizables. (A base de menos gastos de gestión, el ahorro que supone disminuir la medicina defensiva, indemnizaciones razonables y reguladas o baremadas (i), tablas de exclusiones, etc.).

i. Siempre es una vía más a seguir que descarga secundariamente de Juzgados y no interfiere la vía judicial, pues esta otra vía siempre es voluntaria.

Para conseguir estos fines, se ha de actuar con otros criterios no exclusiva ni principalmente jurídicos, sino basados en razones sociales, de solidaridad, comprensión, información, etc., con trámites más sencillos y rápidos (desburocratización), basados siempre en seguros de amplia cobertura (que permitan indemnizaciones más ágiles y elásticas) y con más personalización de cada caso, en contra de la frialdad de la vía judicial, afrontando los hechos con claridad, exactitud y naturalidad (partiendo de un correcto y cuidadoso informe médico) y haciendo una buena planificación económica y de reparto de recursos, dirigida principalmente a indemnizar al perjudicado, con reducción de gastos contingentes y medicina defensiva, como compensación del incremento de casos indemnizables.

Veamos lo que hacen en otros países de más experiencia para intentarlo, prestando atención al Derecho comparado [5]:

Existen múltiples ensayos en los que siempre late la tendencia a desviarse a criterios de responsabilidad objetiva, aunque de alguna manera matizada, regulada, frenada o controlada:

Y así se impone cada vez con más fuerza el criterio de la "responsabilidad sin falta" (Suecia, Nueva Zelanda, Reino Unido, Dinamarca, Finlandia, Noruega, EE.UU.) [I], de cuyo sistema existe una amplia gama de posibilidades y en el cual las víctimas de daños sanitarios deben ser indemnizadas independientemente de que haya existido falta o negligencia. La razón para compensar sería la causa en vez de la falta, lo que lleva aparejado un número mucho más alto de casos indemnizables, por lo que el coste sería mucho mayor. [6]

En cambio, se pretende eliminar parte del enorme precio que supone la medicina defensiva, y por otra parte las tasas de indemnización serían más ajustadas (reducidas) y menores los gastos contingentes (letrados, procuradores, informes médicos, etc.), con lo que en parte podría compensarse el incremento de costes que suponen estos procedimientos.

Estos sistemas rigen en Nueva Zelanda desde 1974, financiados por distintas procedencias, con muy buenos resultados y junto con Suecia fueron los países pioneros en este tipo de indemnizaciones.

La clave de la compensación económica es un daño o enfermedad que ocurre como consecuencia directa de un examen o tratamiento, que no constituya una complicación inevitable, existiendo unas tablas de exclusiones, elaboradas con la asistencia de médicos.

Los resultados de este sistema son eficientes, claros y de coste aceptable, sin que ni un solo paciente haya apelado a los Tribunales, siendo el coste del sistema de 2 dólares por ciudadano y año.

En Suecia, para poder conseguir estos objetivos se apoyan en un importante seguro fundamentado en el compromiso voluntario de las autoridades sanitarias frente al paciente. El Seguro facilita el sistema de indemnizaciones, cuya aceptación es también voluntaria, estructurada en un sistema mixto de conciliación-arbitraje, sin excluir el cauce legal, al que solo se llega en muy contadas ocasiones.

Las reclamaciones se hacen al Servicio de Reclamaciones del Consorcio de Seguros o al 
Consejo de Reclamaciones del paciente. Existe un Tribunal arbitral previo a la vía judicial. De 2440 casos en |99|, solo, 31 llegaron a la vía judicial, resolviéndose 6 a favor del paciente. El sistema de reclamaciones está inspirado en la legislación sobre culpa por negligencia. El personal sanitario presta su apoyo al paciente y realiza toda clase de investigaciones, destinadas a aclarar los hechos y mejorar las medidas preventivas. Los médicos, enfermeras y asistentes sociales que trabajan en los hospitales cumplimentan las solicitudes de indemnización y rellenan los formularios pertinentes en un $80 \%$ de los casos. Todo ello facilitado porque el seguro no está buscando mecanismos para eximirse del pago de una indemnización ni normalmente profundiza en buscar culpables. (CLOTIER C.) [7]

Sistemas similares funcionan en Finlandia (donde desde 1986 existe un moderno sistema de indemnización "sin falta" a través de una Compañía aseguradora (BRAHAMS) [8]; en Noruega, donde existe la posibilidad de estas reclamaciones sin falta en los hospitales y la prevención de la malpraxis se basa en una buena comunicación entre enfermos y personal sanitario (MOLVEN) [9], siendo las enfermeras y personal auxiliar del Hospital las que colaboran y practican las reclamaciones; en Dinamarca, habiéndose introducido un sistema de seguro al paciente con mejoras de sus derechos, considerando actualmente que daños considerados como fortuitos lo sean por negligencia, omisión y falta de información (SEGEST) [10].

En Gran Bretaña se ha intentado un sistema "sin falta", promovido por el Real Colegio de Médicos de Inglaterra, con participación del Estado, a través del Servicio Nacional de Salud, el Departamento de Sanidad, la Organización de defensa del facultativo y el B.M.A. (DIMOND) [I I], pero tal modelo cuadriplica los gastos (FENN) [I2], por lo que se siguen procedimientos "por agravio".

Algo similar ocurre en Francia, que sigue rigiéndose por métodos clásicos, pero a parte de la responsabilidad civil y penal (muy bien definida en el Código Penal), está muy bien estructurada la Jurisdicción Administrativa, con tres niveles: Tribunal Administrativo, Corte de Apelación Administrativa y Consejo de Estado, agotándose en esta vía muchos procedimientos sobre todo de responsabilidad médica hospitalaria, por sistemas de mediación y conciliación, como después veremos (ROUGE) [ I3] FENECH [I 4].

En Alemania rigen los estándares elevados y la inversión de la carga de la prueba en casos graves, limitación de indemnizaciones para daños inmateriales, minimización de costes mediante alta calidad de servicios médicos, y un clima de menor presión para el litigio, con mayor eficacia resolutiva y papel fundamental del perito médico para establecer los estándares, y uso de comisiones de expertos para conseguir peritajes más fáciles y objetivos, evitar acusaciones infundadas y controlar la calidad de los servicios y la educación médica $[15,16,17,18$ 19, 20].

La Unión Europea está también a favor de las soluciones extrajudiciales para la resolución de reclamaciones y ha publicado un documento sobre sanidad y protección de los consumidores que pretende impulsar la solución extrajudicial de conflictos y que en un futuro se aplicará también a los usuarios y profesionales de los servicios sanitarios, pues la solución amistosa de los litigios satisface las necesidades y preocupaciones de los profesionales que desean evitar pleitos judiciales y mantener su clientela. [20]

La Comisión Europea ha puesto en marcha una iniciativa que tiene por objeto completar la política aplicada por los Estados miembros en el ámbito de la sanidad y el consumo, con el fin de alcanzar "un alto nivel de protección de los usuarios, habiéndose unido España a esta iniciativa por medio de una red pública de Tribunales arbitrales de consumo. Se pretende fomentar y facilitar la solución de los conflictos en una fase inicial, de modo que las partes eviten las molestias causadas por la apertura de un procedimiento (judicial o extrajudicial). 
A tal efecto, la comunicación presenta un "formulario europeo de reclamación" destinado a mejorar la comunicación entre los usuarios de los servicios (enfermos) y los profesionales (médicos), con objeto de llegar a una solución amistosa de sus discrepancias, recomendándose que los órganos responsables de la solución extrajudicial de los conflictos sanitarios acepten la apertura de un procedimiento de su incumbencia mediante la simple presentación de este formulario, que en el supuesto de que el diálogo entre consumidor y profesional no lograra una solución del problema, podría utilizarse para iniciar un procedimiento extrajudicial.

La creación de una red comunitaria reduce costes, formalidades, pérdidas de tiempo y obstáculos tales como los problemas lingüísticos encontrados en las reclamaciones transfronterizas. Los sistemas extrajudiciales nacionales (como el Consumer Complaints Boards de los escandinavos, los tribunales arbitrales de España o el Ombudsman de las Compañías de Seguros) se ocupan de reclamaciones muy diferentes, lo que conlleva disparidades en los Estados miembros, que serán menores con este sistema.

En modo alguno podríamos dejar de considerar las modificaciones y matizaciones de estos procederes extrajudiciales en Estados Unidos, aunque solo sea esbozándolos, y que podríamos resumir en:

I.- Sistema basado en falta y regulado por la Administración (mediante expertos con posibilidad de apelación a Tribunales de Justicia) [2।]. Se trata de una alternativa menos abierta, sugerida por la American Medical Association mediante un sistema administrativo basado en la existencia de falta para determinar si los daños causados médicamente han sido debidos a negligencia. Bajo este sistema, un tribunal examinador, auxiliado por informes de expertos, debe determinar los merecimientos del caso y establecer el nivel de compensación. La decisión del tribunal tiene posibilidad de apelación.

2.- Sistemas "sin falta" por vía administrativa: propuesto en principio por BARRY MANUEL [22], reemplazando el sistema basado en la existencia de falta por un sistema administrativo, en el que todas las víctimas de daños sanitarios deben ser compensadas por la pérdida económica, independientemente de que exista falta o no, de modo similar a los accidentes de trabajo o accidentes de tráfico. No es pues necesario que exista falta, sino simplemente que el acto médico haya sido la causa del evento dañoso.

3.- Eventos compensables designados: modificación presentada por HALLEY [I] con restricción de los casos compensables a los denominados DCE (eventos compensables designados), con una lista específica de tipos de daño médico elegidos para compensación, porque es relativamente probable que estén asociados con algún tipo de negligencia.

4.- Compensación acelerada de eventos: es otra modificación muy utilizada en Obstetricia y propuesta por BOVBJERG [23], que indemniza los resultados adversos que médicos expertos determinen que son relativamente evitables, fácilmente identificables y que no causan distorsión en las decisiones a tomar.

Existe también una lista previa de este tipo de eventos.

5.- Por pérdida (incluso sin falta directa), es decir, por riesgo (asumiendo la responsabilidad del mismo la sociedad) (ABRAHAMS) [24]

6.- Arreglos particulares o a través de Cías de todos los tipos. 
Nuestra sociedad (la de nuestro país), demanda asimismo, por las razones aludidas, cada vez con más fuerza y a través de ambas partes implicadas, soluciones alternativas para resolver los conflictos derivados de la malpraxis médica, tratando, en principio, de no tener que acudir a un Juez, o, en su caso, buscar una vía de salida.

Se requieren sistemas más simples y dinámicos, que, a través de un simple acercamiento de posturas, consigan resultados positivos y eviten los problemas importantísimos, que hemos mencionado.

En este sentido se han ensayando nuevos procedimientos que reconocen el derecho de las personas a solucionar sus problemas a su libre disposición, encauzando las reclamaciones por diversos caminos, y así se han hecho a través de las Oficinas Municipales de Información al Consumidor, ante la Comisión Deontológica del Colegio Profesional, mediante carta o telegrama al abogado del paciente y procedimientos múltiples no sistematizados a través de Compañías aseguradoras, Colegios, etc.

En todos los casos se deben comunicar a través del abogado del profesional, que contactará con los interesados o Compañías aseguradoras y formulará la contestación, que proceda.

Son muchas y muy diversas las formas en que un paciente o sus familiares pueden articular su exigencia de responsabilidad por vía extrajudicial, pero no son menos peligrosas que si de una reclamación judicial se tratara, pues en estos primeros contactos y del rigor con que se traten dependerá que la reclamación acabe o no ante los Tribunales.

Por ello se buscan procedimientos que obvien errores que conduzcan a ese fin y de algún modo institucionalizados, sistematizados, legalizados,... y entre ellos están la MEDIACIÓN, CONCILIACIÓN Y ARBITRAJE [25], a los que el colectivo de la abogacía por una parte, los Colegios de Médicos por otra, y otras instituciones estatales o paraestatales están prestando especial atención, y que de algún modo y en algunas de sus modalidades son procedimientos parajudiciales (no es exacto el calificativo, como tampoco el de sistematizados, pero de algún modo está justificado llamarlos así, al no contar con una expresión más exacta, porque tienen cierta base legal y unas normas de funcionamiento definidas en reglamentos), que merecen que le prestemos especial atención.

Tales procedimientos, ya implantados desde antiguo en otros ámbitos del Derecho, en su versión referida a la Sanidad fueron presentados de manera solemne en el VI Congreso de Derecho Sanitario, celebrado en Madrid en Octubre del 99.

LA MEDIACIÓN constituye la fórmula no vinculante más conocida y utilizada, que tiene un especial interés por ser la menos regulada en el Derecho positivo, por admitir mayor debate doctrinal, por su polimorfismo y por ofrecer las mayores y más sencillas posibilidades en la resolución de conflictos.

Según RETUERTO M. (1999) [26], a cuya intervención en el aludido Congreso nos ceñimos, es un proceso a través del cual dos o más partes someten sus diferencias o disputas a la intervención de un tercero neutral, el mediador, con el objeto de que les ayude a encontrar una solución satisfactoria o la menos mala para todos. El mediador no tiene autoridad para imponer su criterio o decisión ni las partes se la reconocen, limitándose a explorar las causas de la disputa y las motivaciones e intereses de las partes para proceder a sugerir o apuntar soluciones, mediante el diálogo que se da a través de su persona.

Se trata de un procedimiento muy antiguamente utilizado en civilizaciones elementales, basadas en principios tribales y comunitarios, que en su versión moderna y actual se inició primero por USA (a mediados de los sesenta), y luego en Europa Occidental, sobre todo en Francia. En su 
formulación reciente, la teoría de la mediación es una respuesta de la postmodernidad a las exigencias de cohesión social. En efecto, en la crisis del Estado Moderno, en la que este se encuentra con grandes dificultades para el ejercicio de su función de regulación y producción normativa, surge la contestación de la legitimidad del derecho racional como fuente de regulación social. Por lo cual trata de buscarse una norma más accesible, reducida a sus justas proporciones y desacralizada como tal y asimismo las instituciones de que dimana, ante las dificultades de regulación legal-racional. Se necesita para ello alcanzar un nuevo sentido jurídico (SOUSA SANTOS) o una nueva "razón jurídica" (ARNAUD).

La mediación, según ETIENNE LE ROY, es más compleja en realidad que la simple descripción que hemos hecho de la misma, presentándose en cuatro estadios, fases o modalidades, y así puede entenderse como práctica de intervención en una diferencia, como procedimiento de gestión de un conflicto, como procedimiento de composición de un litigio o como ideología de pacificación social sobre una base consensual y negociada

La primera de las modalidades es la que mejor responde a nuestra primitiva descripción y se define como "la interposición en una diferencia entre dos o más actores para descubrir un mínimo de referencias comunes que permitan elaborar un acuerdo". El mediador es un tercero neutral, que interfiere en la comunicación bloqueada de las partes, limitándose a establecer las condiciones y medios de una nueva comunicación. El acuerdo que se pueda alcanzar no es obra del mediador y su intervención no entraña ninguna obligación de ejecutarlo para las partes. En el ámbito sanitario se desarrolla normalmente por personas, que, conociendo las circunstancias de ambos implicados estén situados en una posición, que les permita gozar, a priori, de condiciones de objetividad y neutralidad.

Esta forma de alcanzar el acuerdo y su falta de ejecutoriedad son las características que diferencian a la mediación de otras técnicas no judiciales: en la conciliación el acuerdo puede ser propuesto por el conciliador y en el arbitraje, el laudo tendrá ordinariamente fuerza obligatoria.

La segunda de las modalidades es aquélla, en la que se configura como procedimiento de gestión de un conflicto, entendiendo por tal la existencia de una oposición abierta, y aquí, para que sea eficaz la intervención del mediador, debe ser ajeno al sector sanitario implicado y su actuación discreta e incluso secreta si es posible, pero debe aparecer como una figura de "autoridad", y no en función de su lugar en una institución o en virtud de un mandato, sino como consecuencia de la expresión de su neutralidad, objetividad y sentido de la equidad.

Es importante tener en cuenta que el mediador preste más atención a los hechos que a las normas, y a las actuaciones efectivamente realizadas por las partes que a los juicios que estas han dado y dan para justificarlas. El mediador no tiene que juzgar como un magistrado desde la ley, sino desde la comprensión de las condiciones de nacimiento del conflicto, guiar a las partes al encuentro de una solución consensuada.

El tercer nivel analizado se refiere a la mediación como procedimiento parajudicial de solución de litigios, considerando como tales los planteados ante los Tribunales de Justicia.

Esta forma de mediación no se utiliza en nuestro medio, pero es la que ha alcanzado mayores niveles de institucionalización en los sistemas jurídicos occidentales, principalmente en USA y Francia; en ella se produce una especie de descentralización de la justicia, en la que la autoridad del magistrado se delega para la solución de ciertos litigios en instancias locales más o menos institucionalizadas, siempre con la reserva del control del ejercicio de esa delegación en manos del magistrado, a quien en todo caso corresponde otorgar la fuerza ejecutoria a las medidas propuestas por la instancia delegada. Esta modalidad se ofrece como respuesta a la crisis de la excesiva rigidez de la organización judicial y a la lentitud de los procedimientos. 
Este tipo de mediación parajudicial presenta algunos problemas, como son: que el mediador se constituye como brazo armado del Juez y se parece más a los procedimientos de conciliación y arbitraje, donde el mediador en vez de ser elegido por las partes, puede ser impuesto por el magistrado, y la ejecución del acuerdo no depende de su aceptación por las partes, sino de la decisión del magistrado.

Por ello, a esta modalidad de mediación la consideran más como justicia negociada o propuesta que como una técnica o tipo específico de negociación.

Por otra parte, cuando se llega a esta fase de litigios, el grado de enconamiento es grande, en la mayor parte de los casos existen daños que precisan de reparación, y aparece el papel de víctima, invocado por una de las partes cuando no por las dos. Tal proceso psicológico de victimización exige para su superación por el que lo sufre algún tipo de reparación de los que se conocen como "honrar a la víctima".

La última de las acepciones de la mediación hace referencia a su análisis como ideología de la pacificación social, que puede sonar a utopías más o menos voluntaristas: Esta concepción descansa en la hipótesis de que la diversidad y complejidad de la vida social faciliten el desarrollo de modos descentralizados de composición de conflictos, permitiendo también a los ciudadanos volver a apropiarse de los modos de gestión de estos conflictos, lo que implicaría como realidad complementaria el surgimiento de una teoría de prácticas profesionales al margen del campo judicial, que entrañan una ética, unas habilidades y unas responsabilidades específicas distintas e independientes de las judiciales, tratando de construir un discurso que levante como valores morales centrales la disponibilidad para con los demás, la responsabilidad y el altruismo, ensalzando las virtudes sociales de la solidaridad, la dignidad y la generosidad.

En cuanto a las posibilidades de la mediación en el marco sanitario, no existe previsión expresa en el ordenamiento jurídico sanitario español ni en la legislación de protección de consumidores que se refiera a la mediación como técnica de superación de conflictos, pero esta falta de previsión no implica, en modo alguno, imposibilidad de establecer y desarrollar sistemas y procedimientos de mediación, pues el art. 9.2 de la Constitución es norma habilitante suficiente para poder desarrollar dichas técnicas por los poderes públicos, y en el ámbito de la relación privada el principio de autonomía de la voluntad de las partes, consagrada en el Código Civil la permite sin duda alguna.

Sin embargo, el éxito de la mediación no depende tanto de su regulación en el plano normativo como de su aceptación en el ámbito cultural de la sociedad y el sector en el que se inserta.

La concreción de las distintas modalidades mediadoras en el sistema sanitario español es algo que corresponde decidir a los implicados en el mismo: profesionales, empresarios, usuarios, Compañías aseguradoras, etc., de lo que aquí existe importante representación.

LA CONCILIACIÓN es una posibilidad de crear un determinado "germen de consenso" mediante la verdadera conjunción de los intereses en juego, aportándose a las partes, a través de personas o instituciones acreditadas, una alternativa concreta a la vista del examen de los hechos concretos y evaluación de sus repercusiones.

Mediante ella, se trata de poner de acuerdo los ánimos que estaban opuestos entre sí, conformando dos proposiciones, al parecer contrarias.

El conciliador tiene una postura más activa, exhortando a las partes para que lleguen a un acuerdo y velando para que dicho acuerdo se ajuste a las normas generales de validez de los convenios. 
Estaba regulada en la desaparecida ley de Enjuiciamiento Civil en los arts. 460 y sgtes, que siguen vigentes hasta la puesta en vigor de la Ley de Jurisdicción voluntaria, que hacen referencia a los actos de conciliación.

En las reclamaciones directas a la Administración, está inventada la conciliación por la terminación convencional (especie de arbitraje ante la Admón.) (art. 8 de R.D.429/93).

Se trata de comparecer las partes ante el Juez con la finalidad de conseguir la avenencia y evitar el litigio que una de ellas trata de plantear a la otra. En la práctica no ha respondido a las expectativas en el Derecho Civil, habiéndolo hecho en cambio en la Jurisdicción Social.

En el referido articulado se indica la posibilidad, antes de promover un juicio, de intentar la conciliación, ante el Juzgado de $I^{a}$ Instancia o de Paz competente. Se indican normas, plazos y técnica, así como los efectos d la celebración del acto de conciliación, que dependen de su resultado: Sin avenencia ente las partes, queda expedita la vía judicial, y si existe avenencia, lo acordado tiene fuerza ejecutiva entre las partes intervinientes sin necesidad de ratificación ante el Tribunal, y lo convenido por las partes se llevará a efecto por el mismo Juez, cuando se trate de asuntos de competencia del mismo. En los demás casos tendrá el valor y eficacia de un convenio consignado en documento público y solemne.

Contra lo convenido en acto de conciliación podrá ejercitarse la acción de nulidad por las causas que invalidan los contratos.

La conciliación, en todo caso debe ser paso previo al Arbitraje Colegiado, y así se contempla en los Reglamentos de los Tribunales que han iniciado su andadura.

Finalmente, cuando fracasan la mediación o la conciliación y existe un deseo de las partes de solucionar sus problemas derivados de la responsabilidad profesional sanitaria, sometiendo la solución a terceros con facultad de decisión conferido por ellas, está el mecanismo del ARBITRAJE, mediante la determinación de un procedimiento, que respete los principios de audiencia, igualdad y contradicción.

Los Tribunales Arbitrales de Sanidad pretenden ser un método alternativo a la solución actual, que garantice obtener una solución justa, rápida y con fuerza de cosa juzgada y no menoscabe el prestigio de las partes mediante la publicidad que se da a las sentencias judiciales.

El arbitraje se incorpora como figura en la codificación que se lleva a cabo en nuestro país en la $2^{a}$ mitad del XIX y se emplaza en el Código Civil y en la LEC y la Ley de 1953 supuso un avance considerable en la concepción y desarrollo del arbitraje, aunque no hay ninguna razón que justifique que esta nueva regulación se hiciera por Ley especial no codificada, como tampoco lo fue la nueva Ley $36 / 88$, del 5/I2, que derogó la anterior.

El arbitraje sanitario, en un primer intento de conceptualización, según GARCIA HERNANDEZ (2000) [3], se podría definir como "institución jurídica, por la que dos o más personas una de ellas profesional de la sanidad- establecen que la controversia resultante de un acto médico sea resuelta, conforme a un procedimiento legalmente establecido, por árbitros designados voluntariamente por las dos partes y a cuya decisión expresamente se someten, ya sea esta dictada conforme a Derecho o en equidad".

Se trata de un medio que supone la armonía entre el profesional y el paciente, sin necesidad de acudir a la fuerza del Estado y representa un avance evidente del progreso social, de la independencia de los ciudadanos respecto al Estado, del desarrollo de las relaciones médico-paciente y la mutua comprensión de que el médico no desea ningún perjuicio para su paciente, y en caso de surgir un resultado negativo en el ejercicio profesional, están ambas partes dispuestas a reparar el daño causado, sin menoscabo de la honorabilidad del profesional ni del paciente. 
No podemos entrar en modo alguno en el estudio en profundidad del arbitraje médico, y únicamente resumiremos muy esquemáticamente el estudio que del mismo realiza el citado autor del siguiente modo:

En cuanto a la naturaleza jurídica del arbitraje, hay que considerar que se trata de una institución compleja y buena parte de la doctrina se divide entre su naturaleza contractual o jurisdiccional. Para los primeros lo que prima es la voluntad de las partes, que se encuentra en el origen mismo del contrato, mientras que para los que defienden la $2^{a}$ teoría, según FONT SIERRA, " la manifestación de la voluntad de las partes mediante el convenio y posterior aceptación de los árbitros son solo las condiciones, a las que la Ley vincula los poderes jurisdiccionales que otorga a los árbitros, y cumplidas esas condiciones, la atribución de jurisdicción a los árbitros es independiente de la voluntad de las partes y se produce así porque el Estado lo quiere a través de la Ley.

Como características del arbitraje, se citan las siguientes (tomadas de la Ley 36/88):

- Voluntad inequívoca de las partes de someterse al mismo

- Ambito de aplicación que excluye: cuestiones en las que haya recaído resolución final firme, cuestiones sometidas a derecho necesario: penales, administrativas y laborales o aquéllas en las que deba intervenir el ministerio fiscal. Los Tribunales Arbitrales de Sanidad se encargarían de reclamaciones contra los médicos y otro personal sanitario por responsabilidad civil, encargándose de la penal, si hubiera acaecido, los Tribunales Ordinarios.

- Clases de arbitrajes: contractual, "ad hoc", institucionalizado (Colegios profesionales de Médicos o Abogados), de derecho (interpretando la norma jurídica como lo haría un Juez) o de equidad (al saber y entender de los árbitros, sin vínculo a norma alguna, con flexibilidad y libertad de criterios)

- Convenio arbitral: instrumento en el que se plasma el derecho de las personas a solucionar las cuestiones litigiosas de su libre disposición, renunciando libremente a demandar en el orden jurisdiccional ordinario.

- Árbitros: en el Tít. Ill se regula su capacidad, sus incompatibilidades, y su abstención y recusación. Así como su número, que será impar, con tres como mínimo, cuyo Presidente se fijará por las partes o por los mismos árbitros.

- Procedimiento arbitral (Tít. IV), rigiendo los principios de audiencia, contradicción e igualdad. Plazos. Pruebas a instancia de parte o por propia iniciativa. Las fases del procedimiento serán: notificación a las partes, fase de alegaciones, fase de prueba, fase de audiencia y emisión del laudo, que deberá ser congruente, motivado (en arbitraje de Derecho) y notificado fehacientemente a las partes (Tít. V)

- Intervención jurisdiccional o auxilio judicial (Tít. VI), como fase patológica del arbitraje, ya que con dicha intervención falla la filosofía del arbitraje, cuya primera pretensión es no acudir a los Tribunales Ordinarios: por falta de acuerdo en la designación de árbitros, para auxilio en la práctica de pruebas, en recursos de anulación, de revisión o de amparo.

- Tít. VII. Regula un recurso de Anulación del laudo, a fin de garantizar que el nacimiento, desarrollo y conclusión del procedimiento arbitral se ajusten a lo establecido en la Ley.

- Tít. VIII. Regula la Ejecución forzosa del laudo con un sistema lo suficientemente complejo como para encauzar la pretensión de ejecución y la oposición a la misma con las suficientes garantías para ambas partes

- Tít. IX y X. Ejecución en España de Laudos Arbitrales extranjeros y Derecho Internacional Privado. 
CRÍTICA DEL ARBITRAJE: en esquema, señalamos las siguientes ventajas e inconvenientes:

\section{VENTAJAS:}

- Puede evitar el proceso penal (común con todos los extrajudiciales). En todo caso se presume mayor discreción y confidencialidad.

- Formalismo mínimo. Más flexibilidad y elasticidad. No existe procedimiento prefijado, sino el establecido por las partes (63 artículos de la Ley 36/88 vs 2182 de la Ley de E.C.)

- No necesidad de abogado ni procurador en arbitrajes de equidad, y solo abogado en los de Derecho.

- No existen plazos, salvo el máximo de 6 meses para terminarlo.

- Objetividad, imparcialidad y transparencia para las partes, operando los principios de audiencia, contradicción e igualdad.

- No hay escasez de árbitros, y estos pueden ser especializados.

- Mayor rapidez.

- Gastos menores que en vía judicial (i?).

- La voluntariedad que implica conformidad de las partes y la elasticidad evitan que el enconamiento vaya a más. (La posibilidad de cambiar impresiones, hablar y opinar, conocer lo ocurrido, libera tensión).

- Aproximación a Europa.

- Descongestión de Juzgados.

\section{INCONVENIENTES:}

- Falta mucho para que funcionen bien, pues están en estudio. No existe experiencia fiable nacional. Deben acreditar su efectividad.

- Corporativismo. Sobre el mismo existen opiniones contrarias: Según SIERRA DE LA CUESTA [27]cree que "el arbitraje no supone un aumento del corporativismo del sector sanitario y que todo depende de quien sea el árbitro en este proceso, que por supuesto no debe ser alguien que pertenezca al gremio". De modo similar opina RUIZ VADILLO [28]. Hay que tratar de corregirlo de este modo. Por parte de las víctimas, en cambio, existe gran desconfianza en este sentido.

- Neutralidad (i?). Siempre en esta vía existen más intereses y menos independencia. Los árbitros son personas cuyo oficio no es juzgar y pueden ser valedores de las partes.

- No es tan barato como debiera ni tan corto como se quisiera.

- Es más encorsetado y complicado de lo deseable.

- El ser voluntario por ambas partes, lo hace impracticable con frecuencia al no ser del agrado de una de ellas.

- En general, se resta intervención e importancia al médico (no solo como árbitro, sino porque no se hace constar su necesidad como perito, que a nuestro juicio es imprescindible).

En España, los Tribunales de Arbitraje Sanitario tienen una corta existencia y proceden de diversas instituciones y puntos de partida distintos: Colegios de Médicos, Colegios de Abogados, Juntas Arbitrales de Consumo, Comunidades autónomas, etc. 
Entre los Tribunales de Arbitraje Sanitario existentes están los siguientes:

I. Vizcaya. Se inició en 1997 en el Colegio de Médicos. El mayor problema que presenta es el recelo del paciente a un procedimiento creado en la casa del médico, y en la errónea creencia de que es el propio médico o sus pares el que resuelve el conflicto.

Carece de control por parte de la Administración y se somete de plano al Derecho privado.

Su actividad es bastante reducida por estas razones y se prefiere poner el acento en la correcta tramitación de los asuntos, en especial en los primeros casos para tratar de acreditarse.

2. Colegio de Abogados de Madrid. Cuyos estatutos se aprobaron en Julio del 99 y se presentó en el VI Congreso Nacional de Derecho Sanitario en Diciembre del 99. Su creación se ha recibido favorablemente, aunque de modo muy discreto por los colectivos de médicos, pacientes y abogados. En una encuesta realizada por Diario Médico sobre la valoración por médicos, pacientes y letrados sobre su creación, en fecha | $/ 5 / 0$ |, se reflejan resultados poco entusiastas.

3. Por el Colegio de Médicos de Orense se ha puesto en funcionamiento un servicio denominado abreviadamente por medio del acrónimo CONCILIAR, con objeto de resolver las controversias entre los profesionales de la medicina, entre estos y sus pacientes o con otros profesionales sanitarios, mediante la conciliación, la mediación y arbitraje como fórmulas alternativas a la vía judicial. [29]

La celebración de la conciliación será requisito obligatorio para el arbitraje. Si no existe avenencia se acudirá en segundo término a la mediación.

Cuando no existe avenencia tampoco, se podrá recurrir a un arbitraje, que será de equidad, salvo excepciones previstas en el Reglamento.

En cuanto a los árbitros, si el asunto que se debate atiene únicamente al correcto ejercicio profesional de la medicina, los árbitros serán médicos, y si el conflicto es de naturaleza jurídica entre profesionales de la medicina, serán abogados y el arbitraje será de Derecho.

4. Existe un Comisión de seguimiento en Cataluña desde 1993 para indemnización por daño y evitación de judicialización del profesional, bajo la tutela del Colegio de Médicos de Barcelona, cuyas funciones primordiales son el análisis de las praxis médicas reclamadas o de organización, y autorizar, en su caso, acuerdos económicos indemnizatorios de daños económicos ocasionados por actos sanitarios, en los que se observa la existencia de una acción u omisión no maliciosa, pero culposa o negligente del profesional y un nexo causal entre la actividad médica y el daño, siempre que este no sea atribuible a un hecho previsible o inevitable

5. En Cantabria existe una propuesta del Colegio de Médicos para creación de un tribunal de arbitraje.

6.García Hernández, presidente de la Sociedad Castellano-leonesa de Derecho Sanitario propugna una Junta Arbitral de Sanidad creada desde la Comunidad autónoma, que según su criterio debería estar alejada de los Colegios de Abogados y de Médicos, y la vía administrativa sería más imparcial

En Derecho comparado son conocidos los ejemplos de Suecia, Finlandia, Nueva Zelanda y Estados Unidos y últimamente en Méjico, donde se contempla con gran entusiasmo, teniendo el 
beneplácito y apoyo del Gobierno, habiendo creado hace poco más de 2 años mediante norma con rango de ley la Comisión Nacional de Arbitraje Médico (CONAMED) [30], destinada exclusivamente a atender las quejas de los pacientes de todo el país, canalizarlas hacia la mediación y conciliación, y en último extremo arbitrar un laudo que dirima la cuestión si ambas partes aceptan de antemano someterle su discrepancia. En este caso, un gabinete interdisciplinar, compuesto por médicos y abogados hace las veces de árbitro, y todo ello según una normativa arbitral similar a la española.

Desde Junio de 1996 (fecha de iniciación) hasta Diciembre de 1998, la Comisión Nacional de Arbitraje de Méjico (CONAMED) ha atendido 10966 reclamaciones, admitiéndose a 4847 (el 44\%), que se canalizaron en principio para conciliación. Cuando a través de la conciliación no se logra el acuerdo de las partes, se les propone el arbitraje, que puede ser efectuado siempre y cuando se cuente con la voluntad de las partes. En los casos en que no es aceptado el proceso de arbitraje, se dejan a salvo los derechos para que los interesados puedan acudir a otras instancias.

De ellas 4 I se resolvieron mediante árbitros, siendo la decisión favorable para el facultativo en el $68 \%$ de los casos.

Se hace notar que si la cultura del arbitraje en Méjico va muy por delante de España, el volumen de las indemnizaciones va muy por detrás.

Las opiniones sobre estos procederes son muy diversas:

\section{En el VI Congreso D. Sanitario del 99, se manifestó apoyo unánime al Tribunal Arbitral Sanitario del Colegio de Abogados de Madrid. [3। ] Y así: \\ Luis Martí Mingarro (Presidente del Colegio de Abogados de Madrid) llama la atención} sobre la importancia de poder evitar el proceso penal, que supone muchas veces una dramatización permanente para el resto de los días del imputado, y la importancia de poder "pinchar el globo de la tensión pasional" que se origina, por lo que desde el principio los abogados deben buscar la concordia y generar confianza, y recuerda que esta vía es más rápida, más barata y debe merecer la confianza de las partes.

Zamarriego Crespo (Presidente del Colegio de Médicos de Madrid), cree que la promoción de cualquier cauce previo a la vía judicial, que evite en lo posible el enjuiciamiento de los médicos ante los Tribunales, y que además no impida a las partes, llegado el caso, acudir a la vía judicial, siempre es bueno, y debería impulsarse, cuidarse y desarrollarse e insiste en la necesaria colaboración y el papel preponderante de los Colegios Profesionales y de las organizaciones sociales en un proyecto, que requiere como condiciones básicas la objetividad, imparcialidad y transparencia para las partes, un coste económico conocido y asumible, y tiempo máximo de meses y no de años para llegar a una solución final.

Margarita Retuerto, ex Defensora del Pueblo y Vocal del C.G.P.J. muestra sus preferencias por la mediación, que considera como una vía distante del laudo arbitral, que gira en torno a una persona -el mediador- que dirige, pero no impone y que propone soluciones y una reparación rápida, sin buscar la subjetivización de la responsabilidad.

Atela Bilbao [32] (Asesor Jurídico del Colegio de Médicos de Vizcaya): Piensa que el Tribunal de Madrid parte ya con una ventaja al no estar creado en la Casa del Médico, sino en la del Abogado, pues con ello disminuye el recelo del paciente al corporativismo y por otra parte, al ser los abogados el medio de canalización de las reclamaciones, pueden desviarlas a esa vía.

Fernández Varela [30], comisionado de la CONAMED mejicana, cree que el arbitraje es el futuro en materia de responsabilidad profesional y el medio de resolución de conflictos que 
menos deteriora la relación entre médico y paciente, por lo que apuesta por él con fuerza.

Leandro Plaza (Vicepresidente del Colegio de Médicos de Madrid.) [33]: opina que el tribunal arbitral, como vía alternativa a la judicial para resolver controversias sobre daños médicos, es más beneficioso para la Administración, pues el ente público debe ser consciente de que por este medio las reclamaciones se van a solucionar de forma más rápida y menos problemática. Considera que el arbitraje va a dar a la entidad pública una mayor imagen, no como de oponente total, sino como la otra parte que intenta explicar en una reunión con carácter conciliador lo que ha pasado, y en su caso, compensar económicamente al paciente.

EI Prof. F. Pantaleón [34] (Catedrático de D. Civil de Madrid): se debería imponer a los seguros del Servicio Nacional de Salud en el pliego de condiciones del concurso público la aceptación de ofrecer el arbitraje.

La fórmula más sencilla para introducir el arbitraje en la Sanidad Pública es olvidarse de la Administración como demandada y centrarse en la aseguradora de su responsabilidad.

Hay quien da por sentado que el asegurador no querrá someterse al arbitraje, porque le va mejor el retraso que supone un pleito, pero también es un inconveniente mantener abierta la solución de un siniestro durante diez años, si el litigio se resuelve en lo contencioso.

Con esta fórmula se lograría un altísimo nivel de satisfacción de los pacientes y se evitaría el problema de someter a la propia administración a arbitraje, que tiene el inconveniente de someter las incidencias del proceso a la jurisdicción civil.

José Ma Alvarez Cienfuegos (Magistrado del T.S.) [35]: la Ley General de Presupuestos impide a la Admón. someterse al arbitraje al establecer que "no se podrá transigir judicial ni extrajudicialmente sobre los derechos de la Hacienda Pública, ni someter a arbitraje las contiendas que se susciten respecto de los mismos, sino mediante Decreto acordado en Consejo de Ministros, previa audiencia del Consejo de Estado en pleno". Ello impide que la Sanidad se someta ni siquiera a un intento de Conciliación en el Tribunal de Arbitraje de Madrid. Pero esta situación tiene que cambiar, y "la Administración tendrá que ir al arbitraje publico, porque la gente no aguanta el tiempo de los procesos: al consumidor, al usuario, al administrado, no le sirve tener razón dentro de 10 años. La clave para este avance es tan sencilla - y tan complicada- como desarrollar la Ley. La Ley de Régimen Jurídico de las Administraciones Públicas ya prevé la instauración de soluciones mediadoras, pero el Gobierno no ha cumplido el mandato de desarrollarlas en el plazo de seis meses que tenia desde Abril de 1998".

Ruiz Vadillo [28]: expresó sus simpatías al arbitraje, siempre que se desarrolle bien y se generalice, pudiendo producir una considerable disminución de pleitos en la jurisdicción ordinaria, entendiendo que en los primeros momentos de andadura de estos Tribunales arbitrales médicos no es muy acertado que sean los propios médicos los que valoren los daños y perjuicios originados por un comportamiento presuntamente negligente de otros colegas.

Ramón Maciá (magistrado, que desde hace meses trabaja en el estudio de un tribunal arbitral médico en Barcelona) [36], recuerda que hace 15 años los accidentes de tráfico copaban los juzgados de Instrucción y un precedente legislativo de 1989, coronado en 1992, ha hecho que los asuntos desaparezcan de los Juzgados. El legislador decidió que hay un tipo de litigio que se puede sacar de la órbita judicial y llevarla a la del arbitraje y nadie se ha escandalizado; más aún, la norma casi ha pasado inadvertida y resulta eficaz.

Recuerda asimismo que los juzgados de instrucción están atestados de asuntos médicos por razones ajenas al proceso penal, pues en realidad solo se busca una indemnización, aun cuando se escoge para ello la vía que aparece más coercitiva. 
El Prof. Figuera Aymerich [3]: "se debería instaurar en España el modelo de compensación de daños sin buscar responsabilidad como posible solución al grave problema de las denuncias y las responsabilidades. Así el paciente recibirá su compensación o indemnización sin tener que probar la culpa del médico ni de nadie".

García Hernández [37]: cree que existe urgente necesidad de implantar un Tribunal de arbitraje médico con seriedad y rigor. Está en contra de que los árbitros sean médicos, y cree que deben ser técnicos en el tema, y no promovidos por los Colegios Profesionales, sino por la Administración. Los arbitrajes deben ser de Derecho, con rigor en la fundamentación del laudo y correcta ejecución del mismo.

Víctimas de Negligencias Sanitarias [38]: expresa su oposición al T.A. de Madrid por considerar que la iniciativa para su creación ha sido elaborada en forma conjunta entre los colegios de Médicos y Abogados, sin tener en cuenta a los colectivos de las víctimas, que no participarían en el Tribunal. Por otra parte asegura que este sistema no permitiría un recurso posterior de los afectados en caso de no estar de acuerdo con la decisión arbitral.

El Grupo Mixto-I.U. [39] pide al gobierno vasco una ley sobre arbitraje sanitario: dicho proyecto debería fundamentarse en los principios de agilidad, celeridad, eficacia y separación de la fase de instrucción y resolución. Fundan la necesidad de elaborarlo en "el largo tiempo y el complejo sistema de determinación de responsabilidades de las distintas jurisdicciones".

BYRNE (Comisario Europeo de Salud y Protección de los Consumidores) [20]: cree que la creación de una red europea de arbitraje es una importante iniciativa que contribuirá a crear un entorno eficaz y práctico y permitirá reforzar la confianza de los usuarios de la sanidad para la resolución de reclamaciones, estando a favor de soluciones extrajudiciales, pues "cuando las cosas van mal, no es práctico ni rentable utilizar vías de recursos tradicionales".

Diario Médico, en fecha 1/5/200I, publica una encuesta sobre la valoración del Tribunal de Arbitraje sobre Daños Médicos del Colegio de Médicos de Madrid realizada a los propios médicos, a los pacientes y a los abogados, a la que antes se ha hecho referencia, con resultados poco entusiastas sobre el mismo de los tres colectivos encuestados.

Expresar la opinión personal es una osadía, después de las referidas, que pertenecen a importantes personalidades, tan importantes como son muchos de los que reciben este mensaje, pero, hechas estas salvedades, creemos que la mediación y conciliación, cuando son suficientes, no tienen más que ventajas. Son procedimientos ideales. Pero cuando los problemas no pueden arreglarse por estos procedimientos, es más difícil que lo hagan por arbitraje. De todos modos, para que funcionen estos métodos, generalmente son necesarias dos condiciones:

I. Un buen seguro de responsabilidad civil. Esta es la razón del éxito de la vía extrajudicial en países ricos (Países Nórdicos, Estados Unidos, Nueva Zelanda, etc. ), la existencia de seguros con amplia cobertura y seguridad en su respuesta. Ello facilita en alto grado la capacidad de maniobra y en consecuencia la posibilidad de llegar a acuerdos satisfactorios, cuando se cuenta con la base de poder indemnizar adecuadamente. Y para hacer un buen seguro, una de las cosas que hacen falta fundamentalmente es dinero. (Eso explica que los países en donde se han desarrollado estos métodos sean los que son).

2. Un buen informe medico, que tiene ciertas características distintivas y a veces resuelve todo, porque el informe y la personalidad del que lo hace con frecuencia actúan como mediadores o como base y gran fundamento de la conciliación, o como elemento fundamental para el conocimiento real de los hechos. 
Por estas razones y su gran importancia, y más en estas Jornadas, en que se ha prestado tanta atención a diversos aspectos del informe médico en los problemas de Responsabilidad por malpraxis, es preciso constatar su importancia para la vía extrajudicial, y señalar algunas características peculiares, que debe reunir especialmente, tales como:

I. Ser minucioso y exhaustivo en la descripción de los hechos, causalidad, posible culpabilidad, riesgo, etc. La minuciosidad y descripción de los hechos y secuelas es de gran importancia para las partes, porque ven allí reflejados los eventos, por los que pleitean. Cuando se leen los informes a los interesados, comprobamos con frecuencia su satisfacción al comprobar que determinados detalles quedan plasmados en el escrito, y ello les da confianza y les permite comprender otros detalles que juzgaban inaceptables de un modo personal o por desconocimiento. Con ello además "se honra a la víctima", tan importante a veces, como decíamos al hablar de la mediación, para poder acceder o continuar en estas vías extrajudiciales.

2. Inteligible (pues no va a ser utilizado únicamente por Jueces o Letrados, sino por personas mucho menos cultas a veces y por las partes). Por ello debe ser el informe claro, bien definido, concreto $y$, si es posible, objetivo.

3. La valoración del Daño Corporal es aquí menos rígida que en la vía judicial, y, aunque se auxilie el informante de baremos (no de un único baremo) puede hacerse en función también del criterio de responsabilidad (objetiva o subjetiva, por culpa, sin falta, por riesgo, etc.), teniendo en cuenta que aquí no va a existir después un Juez ni un juzgador en muchos casos. En todos casos, para el arbitraje deben ensayarse diversas posibilidades.

En general, la VDC, como todos los demás aspectos, serán mucho más libres, teniendo en cuenta que en estos procederes no se actúa exclusiva, ni siquiera fundamentalmente, con criterios legales, pues, por ejemplo, en la mediación rigen los sociales, de solidaridad, de comprensión, etc.; y en los arbitrajes de equidad más que por normas jurídicas se actúa según el saber y entender de los árbitros, sin vinculación a norma alguna, a la hora de valorar los hechos y las pretensiones del médico y paciente.

Con ello se han esbozado, ya que no ha existido otra pretensión, una serie de aspectos, de ventajas, inconvenientes, sistemática, características, etc. de algunos de los más conocidos o sistematizados procedimientos, que constituyen esta vía alternativa a la judicial para dirimir problemas y asuntos relativos a la responsabilidad médica. No es fácil decidirse ni definirse sobre sus posibilidades y utilidad, pues en realidad cada cual los interpreta según la función que desempeña, y los intereses que persigue.

\section{BIBLIOGRAFÍA:}

I. Halley M. Martin et al. "Medical Malpractice Solution: Systems and Proposals for injury compensation". The New England Journal of Medicine (N Engl J Med) Vol 322 № 9, 1990 pg 639-64l.

2. Echániz Salgado, I. "Mediación, conciliación y arbitraje: isoluciones para elo futuro? El papel de la Administración". VI Congreso Nacional de Derecho Sanitario. Ed: Asociación Española de Derecho Sanitario (AEDS), 2000. Ps III-II4.

3. García Hernández T. "Manual del médico clínico para evitar demandas judiciales" Edit. La Ley Actualidad, 1999. Pg 329-354.

4. Jacobson Peter D."Medical Malpractice and the Tort System".JAMA,vol.263,1990,pg 2180.
5. Hernández Moreno J. et al. "Malpraxis médica. Conceptos personales y consideraciones sobre su problemática". Cuadernos de Medicina Forense ${ }^{0} 4$. 1999. Sevilla. Ps 48-55.

6. Jornet J. Malpraxis.T.IV. Ed. Ancora. Barcelona, I995, pg. 49-52.

7. Cecil Clothier. "Medical Negligence and no-fault liability". The Lancet, 1989, ps 603-5.

8. Diana Brahams. "No fault compensation Finnish style". The Lancet, 1998, ps 733-6

9. Molven 0. "Fairness of compensations.Possibilities for patiens injured in Hospitals claim compensation". Tidsskr-Nor-Laegeforen. Vol III (8), pg 992-4. 1991. 
10. Segest $E$. "Patien complaints: some aspects of the evaluation of physicians conduct by the Danish National Board of Healt". Med Law, vol II, pg 57-65, 1992.

II. Dimond B. "Standards setting and litigation". Brit.J.Nurs.Vol 3, pg 235-8,1994.

I2. Fenn P. et al. "Estimating the cost of compensating victims of medical negligence". Brit. Med.J. vol 309 , pg 389-91, 1994.

13. Rouge D. Et al. "Responsabilité de I' interne agissant par delegation". J. de Med. Legal Droit Medical, t.34, pg 3-4, 1994.

I4. Fenech M. "Evolution de la jurisprudence en matiere de responsabilité medical. J. de Med. Legal Droit Medical, t.33, p 2.1990

15. Martinius ]. "Requests for compensation for inmaterial danmage". Z.Kinder. Jugenpsiquiatry. Vol 23 pg 4-8, 1995.

16. Kreinewefers H. "Medical responsability. An overview of recent legislation". Versicherungsmdizin. Vol 46. Pg 37-43, 1994.

17. Meyer D. "The Behavior modifiyng influence of malpractice effects on choice of Technology".'Gesundheitswesen Vol 57, pg I-7, 1995.

18. Schreiber H.L. "The standard of required medical responsability as an instrument in malpractice casses". Versicherungsmedizin Vol 47, pg 3-5, 1995.

19. Freund JF et al. "Expert commission for questions of phisician malpractice". Fortschr. Med.Vol 108, pg 633-7, 1990

20. David Byrne. "La Comisión Europea a favor de las soluciones extrajudiciales". Diario Médico. Normativa. 28/3/2000

2I. AMA/Speciality Society Medical Liability Project. "A proposed alternative to the civil justice system for resolving medical liability disputes: a fault-based, addministrtive system. Chicago: American Medical Association, 1998

22. Barry Manuel M."Profesional liability: A no-fault solution". New Eng. J Med., 1990, vol. 322 pg.627-31

23. Bovbjerg Randall R. et al. "Obstetrics and Malpractice. Evidence of the performance of a selective no-fault system", JAMA vol.265 $\mathrm{n}^{0} 21$ pg. 2836-43.1991.

24. Abraham Kennth S. "Medical liability reform".JAMA vol $260 n^{0}$ I, pg 68-72.1988
25. Retuerto Buades M. "La perspectiva de los consumidores y usuarios". VI Congreso Nacional de Derecho Sanitario. AEDS, 2000, ps II5-126.

26. Zamarriego Crespo J. "Mediación, conciliación y arbitraje. Su importancia en el ámbito sanitario". VI Congreso Derecho Sanitario Ed:AEDS, ps. I27-I3I,2000

27. Sierra de la Cuesta I. "El arbitraje no tiene por qué aumentar el corporativismo médico".

Diario Médico. 20/3/2000.

28. Ruíz Vadillo E. "Il Encuentro sobre Resp.Civil y Penal de los Médicos".Diario Méd. 24/4/98

29. Estatutos del Servicio de Conciliación, Mediación y Arbitraje del Colegio de Médicos de Orense. Diario médico 25///2000

30. Fernández Varela H. "La conciliación y arbitraje de los daños sanitarios en México". Diario Médico 29/3/1999

3I. VI Congreso Nacional de Derecho Sanitario. "Apoyo unánime a la mediación y al arbitraje. Diario Médico. Normativa. 26/I01999.

32. Atela Bilbao A. "Arbitraje: rigor y abundancia". Diario Médico. Normativa .4/12/98.

33. Plaza L. "La vía del arbitraje es más beneficiosa para la Administración que acudir a los Tribunales" Diario Médico 13/3/2000.

34. Pantaleón F. "Se debería imponer a los seguros del SNS que ofrezcan el arbitraje". Diario Médico. Normativa. 26/3/99.

35. Alvarez-Cienfuegos J.M. "La Administración tendrá que ceder y arbitrar". Diario Médico. Normativa.6/6/2000.

36. Maciá R. "II Encuentro sobre Responsabilidad Civil y Penal de los Médicos".Diario Médico.24/4/1998.

37. Víctimas de Negligencias Sanitarias, en contra de un Tribunal de Arbitraje sobre Responsabilidad médica. Diario Médico I7/II/99.

38. García Hernández T. Congreso Sanitario Cast.-León. DiarioMédico 29/32000

39.Alvaro Ortega. "IU pide al Gobierno Vasco una Ley sobre Arbitraje Sanitario". Diario Médico. 10/12/1999. 